\title{
Regional Economic Development and Industrial Resources Optimization and Integration
}

\author{
Li Wang \\ Chongqing Business Vocational College
}

\begin{abstract}
The openness of economic development has become a prominent feature of China's economic development. The regional economic development zone, such as Pearl River Delta, Yangtze River Delta and Bohai Sea region, has become the important force that leads China's economic development. Adjacent provinces and cities have gradually formed a contiguous economic development area. To maintain the healthy development of regional economy, we need to solve the optimization and integration of regional resources first. Regional economic development has inseparable relationship with industrial resources optimization and integration.
\end{abstract}

Keywords-regional economy; resource allocation; natural resources; optimization and integration

\section{INTRODUCTION}

The optimization and integration of resources is an important strategy to enhance the vitality and sustainability of regional economic development, and construct the economic structure system of integrating regional economic development and industrial resources with the government as the development orientation, industrial structure adjustment as concrete measures, and optimization and integration of resources as the direct way. The orderly combination of economy and resource of different provinces and cities helps to promote the regional economy to achieve stable and rapid development. Unbalanced economic development is a prominent problem in the current economic development of our country. The quality and speed of economic development in the eastern coastal areas are better than that in the central and western regions. How to achieve effective linkage between regional economies, promote industrial structure optimization and upgrading, and achieve balanced economic development, has become an important issue now.

\section{REGIONAL RESOURCE INTEGRATION MODEL TyPE ANALYSIS}

\section{A. Natural Resource-led Industrial Resources Integration Model}

Natural resource-led resource integration model refers to taking the acquisition and use of natural resources as the motive power in the development process of regional economy, letting natural resource be the core driving force of economic development[1]. The development of regional economy is based on the excavation and use of existing natural resources, and plans and introduces other resources that regional economy development needs while focusing on the local industrial resources. Natural resource-led industrial resource integration model is under the premise that local resources have advantages, the development, utilization and allocation of natural resources become the key to regional economic development. If the regional economic development is at the initial stage, natural resource-led industrial resource integration model is very conducive to the rapid growth of economy in short term. However, with the continuous development of regional economy, the cost of natural resource development is increasing, so is the destructive effects of industrial production to environment. At the same time, the excessive development of local natural resources industry will undoubtedly affect and restrict the diversified development of regional industries, leading to single regional industrial structure and weak industrial integration capacity. Natural resource-led regional economic model is likely to cause the imbalance of regional product supply and demand. The added value of resourcebased industries is low, the bargaining power of their products is weak, and their sales are easily affected by market fluctuations.

Overall, the advantages and disadvantages of natural resource-led industrial resource integration model are obvious. The advantage lies in that the natural resource industry develops quickly and has high returns when the market is in the rising trend. The disadvantage lies in that the natural resources industry is highly cyclical, and has great destructive effects on environment and lacks of sustained force. If the regional economy is too dependent on the development of natural resources industry, the overall industrial health and economic sustainability will be relatively poor.

\section{B. Social Resource-Led Industrial Resources Integration Model}

The social resource-led industrial resources integration model generally refers to regional economic overall development model which takes full development and use of social resources as the focus of development, social resources as development basis of regional economy and market need as target. The community resource-oriented industrial resources integration model has very outstanding effect on resource elements integration, which is conducive to the steady and rapid development of economy and society. The social resource-led industrial resources integration model is applied to areas where natural resources are relatively poor. The lack of natural resources makes some areas unable to rely on natural resources to pull the region's overall economic development when developing economy. Under the pressure of development, areas which lack of natural resources choose social resource- 
led industrial resources integration model, combine it with the actual situation in the area and develop industries in accordance with market needs. Social resource-led industrial resources integration model is an industrial resource integration model adopted by most regions[2]. And if the natural resources industry integration and social resources industry integration can be effectively combined in the region, it will significantly enhance the regional economic competitiveness.

\section{Open Industry Resources Integration Model}

Open industrial resources integration model refers to the model in which acquisition and use of resources have close relationship with external resources or economic development in the process of regional economic development, and internal and external resources are effectively combined to promote the development of regional economy. The outstanding characteristics of open industrial resources integration model are reflected in following aspects: firstly resources that the region needs comes from outside of the region, including natural resources, human resources and other resources. It realizes the stable development of regional economy through the acquisition of resources outside the region; secondly transfer part of the industrial projects outside the region in the process of regional industrial development, and realize the combination of industries in and out of the region, so as to increase the value of industry resources. At the same time, open industrial resources integration mode can also make full use of external market demand to guide the internal industrial resource allocation of the region, and provide products or services and output natural resources, technical resources and human resources for external market through industrial layout adjustment, so as to promote the region's economic growth[3].

In open industrial resources integration model, natural resources and social resources can be transformed into products or services for cross-regional flow or transfer, so as to optimize the allocation of resources and enhance the efficiency of economic development. The typical example of open industrial resources integration model is the industrial resource integration model of China's Yangtze River Delta region. The location of the Yangtze River Delta is not the region where the natural resources are very concentrated. The natural resources in the region are difficult to meet the actual need of regional economic development. Most of the energy and minerals are dependent on the external supply[4]. The fundamental reason that Yangtze River Delta has been able to have long-term stable development is because of its strong regional economic integration ability, which can effectively attract external resources, and also because that at the same time it can optimize and upgrade industrial layout according to the basic needs of the external market. After access to natural resources, the Yangtze River Delta also has very strong ability to absorb human resources. The development of industry can't be separated from the protection of human resources, and the more developed manufacturing industry of Yangtze River Delta is relying on good technical resources and substantial human resources.

\section{Closed Industrial Resources Integration Model}

Compared to open industrial resources integration model, closed industrial resources integration model is a relatively backward industry resource integration model. Generally, closed industrial resources integration model refers to that the acquisition of resources and industry development power are more from within the region in the process of internal economic development. One of the prominent features is that the resources input and output activities within the region are relatively few. Closed industrial resource integration model is only a relative concept, because currently completely closed development model is rare. In the sustainable development process of modern science and technology, opening is a prominent label of economic development. If the closed development mode is implemented in a region, it will undoubtedly seriously affect the quality of development in the region. At present, in China's domestic regional economy, regions with closed industrial resources integration model are mostly concentrated in the central and western areas. The industrial resources integration of these areas shows some closed features. In regional development process, the introduction and outflow of natural resources, human resources and technical resources are relatively small. The effect of economic diversified development is not obvious.

\section{E. The Relationship of Regional Economic Development and Industrial Resources Optimization and Integration}

The regional economy development is the key to the steady improvement of macroeconomic quality and aggregate. Under the background of industrial structure adjustment, better playing the guiding role of regional economic development has irreplaceable key role in industrial resource optimization and integration. Regional economy refers to the production complex established by the combination of internal factors and external conditions of economic development within certain regional scale. Regional economy must have a certain regional scope, so as to form a economic development zone with stable development elements and reasonable resources and industrial allocation. Industrial resources mainly include mineral, energy, water resources and human resources. Industrial resources generally refer to the various resource elements needed for industrial operation, including tangible resources and intangible resources. In general, industrial resources include resources of all enterprises within the industry[5].

The optimization and integration of industrial resources determine the quality and effect of regional economic development to a certain extent. The central and key industries established in the process of regional economic development will become the benchmarks for the integration and allocation of industrial resources within the region. In order to better promote the development of regional economy, the optimization and integration of industrial resources should meet the trend of overall economic development, and serve the regional economic development. Regional economic development needs to establish a good coordination mechanism, avoiding the irrational allocation of industrial structure and excessive exploitation and utilization of resources within the region. How to form a leading industry within the regional economy and core power of internal development is 
the problem that needs to be paid attention to when vigorously developing the regional economy. Industrial resource optimization and integration is a issue that a region, city or development zone should all fully consider at all levels. Fundamentally speaking, the harmonious development of regional economy is the result of reasonable allocation of industrial structure and rational utilization of industrial resources. For example, the world's famous industrial area Ruhr industrial area began to upgrade the industrial area in the late 1960s. It enhanced the overall development level of industrial area and drove the economic development of surrounding areas through resources optimization and rational distribution of industry. The development of Ruhr Industrial Zone has certain reference significance for the development and construction of the old industrial area in Northeast China. And as a regional economic development zone with heavy industry as the industrial base, the industrial resources optimization and integration of Ruhr industrial area promoted the regional economic development and played a leading role to a certain extent.

In general, promoting regional economic development is the fundamental purpose of industrial resource optimization and integration. And the rapid development of regional economy has also brought opportunities for industrial resources optimization and integration. Regional economic development and industrial resources optimization and integration are an overall problem, and have mutuality and linkage. The healthy development of regional economy depends on reasonable allocation of industrial resources, and industrial resources optimization and integration also provide a guarantee for the balanced development of regional economy.

\section{THE IMPACT OF INDUSTRIAL RESOURCE OPTIMIZATION} AND INTEGRATION ON REGIONAL ECONOMIC DEVELOPMENT

\section{A. The Excessive Use of Natural Resources and Rapid Development of Regional Economy}

In the context of resources integration, regional economic development will maintain a trend of rapid development at a certain stage. But with the excessive use of natural resources, and even destructive development and utilization of resources, regional economic growth will show instability. In the short term, the economy will continue to grow, but if things continue this way, the health degree of regional economic development will decrease, and the regional industrial structure develop towards an irrational direction, ultimately forming the industry pattern and production methods that are not conducive to the long-term development and leading to the decline of regional economy. The overuse of natural resources is actually a kind of predatory resource integration. Promote regional economic development through the rapid development and utilization of natural resources. This short-term economic growth mode does not meet the overall requirements of sustainable development. At present, there are declined cities or regions because of natural resources depletion all around the world. Most of the natural resources are non-renewable resources. Once excessively developed and used, it's no doubt like killing the goose that lays the golden eggs. It will eventually leads to the development of regional economy going in the opposite way.
And the excessive development of natural resources is also likely to cause the overall environmental pollution, and have a serious impact on the regional development environment, letting the regional economy lose the attraction of development.

\section{B. The Integration of Innovative Resources and Sustained and Stable Development of Regional Economy}

Based on the clear understanding of regional economic basis, the integration of innovative resources focuses on the absorption and introduction of the deficient resources in the region in the process of regional economic development, at the same time it pays attention to protective development, avoiding the excessive use of natural resources. One of the outstanding features of innovative resources integration is the application and promotion of science and technology to realize the efficient utilization of natural resources, improve the availability of resources and reduce development costs. The integration of innovative resources is essentially the green development of the industry. The rational development and utilization allow the resource supply and industrial structure within the region to develop in a balanced way, so as to promote the gradual optimization of regional industrial structure and enhance the competitiveness of regional development and regional economic anti-risk ability, promoting the sustainable development of regional economy. When the industrial resources within the region are effectively integrated and the regional economy gets into a stable and stable development period, the realization of industry's innovative development will benefit the upgrading of the traditional resource integration model within the region, so that the integration of innovative resources can become the fundamental power of regional economic development. If the traditional resource integration model has entered a mature period, and not easy to quickly achieve the transformation of resource utilization model, we need to conduct resource integration around the leading industry within the region and increase investment and guidance efforts to make money flow into the innovative industries.

The integration of innovative resources is of great significance to the sustained and stable development of regional economy. Whether it is relatively rich in natural resources or areas with scarce natural resources, they all can enhance the natural utilization of the region and reduce resource development costs through promoting the integration and utilization of innovative resources, so as to achieve the sustainable and healthy growth of regional economy and reduce the influence of excessive development and utilization on regional economic growth.

\section{Single Resource Integration and Regional Economic Development Risk}

Single resource integration generally refers to the excessive dependence on one kind or category of resource in the process of regional economic development, which leads to the unreasonable integration of industrial resource and industrial structure not being able to meet the objective requirements of sustained economic growth. The effect of single resource integration reflects in the detailed process of regional economic development, such as imbalanced development of regional 
economy and excessive occupation of single resource-led industries. Once the demand for the resource shows market fluctuations or the resource is in short supply, the regional economic development will definitely face serious difficulties. In the process of regional economic development all around the world, we can easily see city or economic zone with obvious resources or industry labels such as coal and steel cities. In essence, single resource integration does not simply refer to the dependence on natural resources. The dependence on social resources can also constitute the basic form of single resource integration, such as dependence on human resources. The regional economic development of some cities in China depends on human resources too much, especially the manufacturing industry. It can be said that human resources have become the basis of regional economic development. The labor shortage that repeatedly happens these years also belongs to the risk of regional economic development caused by single resource integration. Examples at home and abroad have showed that single resource integration has a very significant impact on the sustainable development of regional economy. The potential development risk has finally determined the trend of regional economic development to a certain extent. In the natural resource-led industrial resource integration model, it will inevitably lead to the decline of regional economy if natural resource is oversupplied in a long term. Industries in the region will generally be depressed with the demand fluctuations of product or service. At the same time, industry structure will lose balance, and the unstable development of economy will become the region's main development characteristics. In general, single resource integration is not a very good industrial resource integration mode for the steady and healthy development of regional economy. The internal risk is very obvious. With the sustainable development of the social economy, the current single resource integration model is no longer in line with the objective environment of economic development. Some of the regions that take single resource integration as the basic mode of industrial resources have begun to carry out the necessary industrial restructuring and upgrading, working hard for the transformation of development model.

\section{Comprehensive Resource Integration and Harmonious Development of Regional Economy}

Comprehensive resource integration generally refers to that under the basic model of reasonable utilization and optimization and integration of resources, the standardized utilization of natural resources and rational allocation of social resources are both considered. It highlights the comprehensive allocation and cycle use of resources, making sure that the efficiency of economic development and utilization efficiency of resources stay on the same pace. Comprehensive resource integration pays more attention to the protection and cultivation of resources. It constructs industrial structure in line with the actual situation of the region through the optimization and integration of resources, so as to promote the overall and harmonious development of regional economy.

Comprehensive resource integration is a common resource integration model in the current regional economic construction. The comprehensive resource optimization and utilization takes advantage of the sustainable and coordinated development of the economy. Therefore, its actual effect is more prominent and conforms to the overall requirement of circular economy construction. Based on the actual situation of the region, achieve a reasonable industrial layout through the introduction of natural resources and effective development of social resources, promote the sustainable development of industries based on market, so as to enhance the overall economic level of the region. Scientific and technological innovation is the key that comprehensive resource optimization and integration model can be effectively applied. Therefore, on the whole, the main features of comprehensive resource integration are innovation and rationality. It guarantees the effective development of natural resources and enhances the efficiency of social resources to the greatest extent. With the same proportions of resource investment, it promotes the overall economic growth, and achieves a comprehensive breakthrough in speed and quality.

\section{Proposals to Play the Promotion Role of} INDUSTRIAL RESOURCES OPTIMIZATION AND INTEGRATION IN REGIONAL ECONOMIC DEVELOPMENT

\section{A. Achieve a Balanced Allocation of Resources to Effectively Highlight the Sustainable Growth of Regional Economy}

The internal factors that regional economy can maintain a steady trend for a long time must include the key factor of balanced allocation of resources. Throughout the world's economic development zones which can maintain decades or a hundred years' balanced development, such as China's Yangtze River Delta, Pearl River Delta and German's Ruhr Industrial Zone, they all achieved the rational and balanced allocation of regional industrial resources. The Yangtze River Delta region is not rich in natural resources. But in the development process, the Yangtze River Delta focuses on the allocation and integration of resources, and gradually forms a industrial structure system in line with the characteristics of the region in the development process. It has achieved the comprehensive integration of resources, and let industry development effect become more prominent. The region's overall economy has a sustained development momentum, full of vitality. As a veteran industrial area, the iron and steel industry is the main industry of German's Ruhr Industrial Zone. In the overall development process of the industrial zone, Ruhr has also experienced several times' resources allocation. It keeps improve the quality of industrial resources, which ensures that the industrial zone has long-term stable development.

From the successful cases, it is not difficult to find the prominent feature of a sustained and stable regional economic development state is their advanced regional industrial resources optimization and integration model. Single resource integration and other backward resource applications have been completely eliminated, and comprehensive resources optimization and integration and other modern industrial resource allocation models have become the mainstream. In the development process of Yangtze River Delta and other regions, the balance of resource allocation is an important advantage of regional economic development. Practice proves that if we 
want to achieve the balanced development of resource allocation, we should first ensure that the necessary resources for regional economic development form a diversified system, so as to achieve a comprehensive allocation of resources, ensuring the diversification of industries and reducing the direct influence of industrial risk on the entire regional economy. Human resources, natural resources, technical resources, capital resources are the four recognized basic resource elements that are essential for development. At a deeper level, in addition to the four recognized resources, internal resources such as policy resources, institutional resources and resource recycling are equally important. If regional economic development wants to maintain sustainability, it must avoid single economic structure or industrial structure imbalance, and ensure the coordinated and sustainable development of economy.

\section{B. The Use Efficiency of Core Resource Determines the Effectiveness of Regional Economic Development}

In the process of regional economic development, whether it is relying on social resources or natural resources, most of the regional economic belts have its core resources, such as coal resources, human resources, technical resources, etc. Enhancing the use efficiency of core resources is the key to ensure the sustainable and effective development of regional economy. Outstanding resource advantages allow regional economic development to be established based on the rich industrial resources, so as to enhance the core competitiveness of regional economy and promote the rapid economic development. In a deep sense, the current core resources are more social resources, rather than natural resources. The fundamental reason is that the economic development structure built based on natural resources is lack of sustainability. Throughout the current situation of regional economic development, technical resources and human resources have basically become a basic resource guarantee for regional economic development. Core resources have become the benchmark for regional industrial layout. After identifying the core resources of regional economic development, we need to further enhance the use efficiency of resources to highlight the priority of core resources, achieving the high-quality development of regional economy.

\section{Achieve a Reasonable Allocation of Social Resources and Natural Resources to Enhance Regional Economic Development Momentum}

With the accelerated pace of industrial restructuring in China, the mode of economic growth gradually change from extensive model to intensive model. In order to ensure the sustained economic growth, achieving a reasonable allocation of social resources and natural resources will be the key to enhance the quality of regional economic growth. For industries relying on natural resources, we need to change its development model, limit the destructive development of resources and enhance the rational allocation of resources. We should not pursue the short-term rapid growth. We need to ensure the balanced improvement of speed and development quality. At the same time, we need to improve human resources quality. Regional economic growth is determined by the quality of human resources to a certain extent. In terms of social resources such as human resources, the realization of talent introduction system improvement and innovation will undoubtedly make regional economic development have vitality. When the allocation of social resources and natural capital achieves its balance, the regional economic development momentum will be more abundant, conducive to the sustainable and long-term development of regional economy.

\section{CONCLUSION}

In short, we need to achieve a balanced allocation of resources, and strive to improve the efficiency of the use of core resources and have social and natural resources optimized and allocated reasonably. Only in this way can we realize effective linkage between regional economies, promote industrial structure optimization and upgrading and achieve balanced economic development.

\section{REFERENCES}

[1] Zhang Dongdong. China's Resource-based City Industrial Transformation Research [J]. Land and Natural Resources Research. 2006 (03)(In Chinese)

[2] Song Xiaowu. Vigorously Promote the Sustainable Development of Resource-Based Cities in China [J]. Northern Economy. 2006 (13) (In Chinese)

[3] Zhou Jianxia; Li Jinying; Zhang Xiying. Fiscal Policy Suggestions for Coordinated Development of Regional Economy during the Twelfth Five Year Plan Period[J]. Chinese Township Enterprise Accounting .2011 (03) . (In Chinese)

[4] Wang Lili. China's Regional Economic Development [J]. China's New Technology and Products .2009 (16) (In Chinese)

[5] Zhang Hongquan. Countermeasures for Regional Economic Development Imbalance [J]. Economic Journal .2010 (10) (In Chinese) 